\title{
Aspectos fisiopatológicos da retenção de ovos em Jabutipiranga (Geochelone carbonaria Spix, 1824)
}

\author{
Fisiopathological aspects of egg retention in South American Red-footed Tortoise \\ (Geochelone carbonaria Spix, 1824)
}

\author{
Carlos Alexandre Rey Matias ${ }^{1}$ Mário Antônio Pinto Romão² \\ Rogério Tortelly ${ }^{3}$ Sávio Freire Bruno ${ }^{2}$
}

\section{RESUMO}

Das enfermidades que acometem o sistema genital de répteis, a retenção de ovos tem grande prevalência em quelônios. Neste trabalho, são analisados quatorze casos de retenção de ovos na espécie jabutipiranga (Geochelone carbonaria Spix, 1824), mantidos como animais de companhia, os quais foram atendidos na Policlínica Veterinária da Universidade Federal Fluminense (UFF) entre os anos de 1999 e 2003. Dos fatores que provocam ou favorecem a ocorrência dessa distocia, foram avaliados: em relação aos ovos retidos, a presença de ovos com alterações de formato e de tamanho aumentado e hipercalcificação das cascas; em relação aos fatores predisponentes, foram analisados fatores ambientais, sinais nos pacientes relacionados à ocorrência de doença osteometabólica, presença de corpo estranho ou fezes ressecadas no trato gastrintestinal, bem como a associação da retenção de ovos com prolapso de oviduto. A utilização de técnicas radiográficas no diagnóstico definitivo da retenção de ovos e no direcionamento da sua resolução mostrou-se indispensável nos casos estudados. Quanto ao tratamento, duas condutas foram consideradas: a utilização de ocitócinos e a intervenção cirúrgica. Da análise dos fatores que favorecem a ocorrência da distocia, conclui-se que a manutenção dos animais em ambientes com substrato rígido foi decisiva.

Palavras-chave: jabuti, Geochelone carbonaria, retenção de ovos.

\section{ABSTRACT}

Egg retention is a disorder that affects the genital system of reptiles, with a great prevalence in chelonians. These work analyses fourteen cases of egg retention in South American Red-footed Tortoise (Geochelone carbonaria Spix, 1824) maintained as pets that had been attended in the Veterinary Clinic of Universidade Federal Fluminense (UFF) between 1999 and 2003. Among the factors that contribute to the occurrence of this dystocia are aspects of the retained eggs such as shape abnormalities, size enlargement and thickened shells were analyzed, as well as poor environmental condition, metabolic bone disease, gastrointestinal foreign body and parched feces, that can predispose to egg retention. Both therapeutic procedures and the presence of prolapsed oviduct were analyzed. The use of radiographic techniques for both diagnosis and therapeutic decisions in egg retention were fundamental in the studied cases. Concernig the treatment, two procedures were taken into account: the use of oxytocin and the surgery. Regarding the factors that contribute to the dystocia occurence, it was concluded that the maintenance of animals in ambients with rigid substrate was decisive.

Key words: tortoise, Geochelone carbonaria, egg retention.

\section{INTRODUÇÃO}

O estudo dos répteis vem ganhando cada vez mais importância, tanto por questões conservacionistas quanto pelo aumento do interesse em sua utilização como animais de companhia. Os jabutis são quelônios de hábitos terrestres, pertencentes à família Testudinidae, a segunda maior família da ordem Testudines em número de espécies (ERNST \& BARBOUR, 1989), e representam uma grande proporção dos animais atendidos na clínica de animais selvagens. No Brasil, o jabutipiranga (Geochelone carbonaria Spix, 1824) é provavelmente o quelônio que mais tem sido mantido em cativeiro como animal de estimação, devido a fatores culturais e amplo comércio ilegal (PINHEIRO \& MATIAS, 2004).

1Programa de Pós-graduação em Patologia e Reprodução Animal, Faculdade de Veterinária (FV), Universidade Federal Fluminense (UFF), Rua Vital Brazil Filho, 64, 24230-340, Niterói, RJ, Brasil. E-mail: camatias@terra.com.br. Autor para correspondência. 2Departamento de Patologia e Clínica Veterinária, FV, UFF, Niterói, RJ, Brasil.

${ }^{3}$ Departamento de Patologia, FV, UFF, Niterói, RJ, Brasil. 
Enfermidades associadas ao sistema reprodutor de jabutis, dentre elas a retenção de ovos, são um dos principais problemas que acometem esses animais quando mantidos em cativeiro. Os processos patológicos que envolvem a retenção de ovos relacionam-se a diversos fatores. Ovos grandes ou deformados, trauma, infecção bacteriana, distúrbios endócrinos, atonia muscular e fotoperíodo anormal são causas potenciais para a retenção de ovos em répteis. Somam-se ainda como causas desse processo certas influências ambientais desfavoráveis, em especial a falta de um local adequado para a confecção do ninho e temperaturas inadequadas (PRITCHARD, 1979; BENNETT, 1989; BROWN \& MARTIN, 1991). Outras causas incluem ovos de casca quebrada, bolos fecais, pedras no cólon ou no reto que obstruam o canal pélvico, litíase vesical, neoplasias ou lesões granulomatosas no aparelho reprodutor, assim como estreitamento de pelve devido a fraturas ou doença osteometabólica (FRYE, 1991). Além disso, quadros de desnutrição e desidratação podem contribuir no referido processo (MADER, 1996; BRUNO et al., 1997). Em condições inadequadas de cativeiro, os ovos podem ficar retidos por tanto tempo que se tornam hipercalcificados.

ZWART \& VORSTENBOSCH (1995) descrevem que anormalidades na casca dos ovos de répteis são freqüentes e que a sua ocorrência implica sérias conseqüências para a viabilidade e a taxa de nascimento. Ovos de tamanho variado e com defeitos de casca, tais como: casca áspera, casca fina, deposição de cálcio em volta dos poros e ovos com múltiplas camadas de casca são algumas das variações morfológicas descritas como anômalas em quelônios, as quais podem dificultar a oviposição. O conhecimento das interações entre o meio ambiente e os padrões hormonais das espécies é insuficiente para explicar a ocorrência destas anormalidades.

O prolapso de oviduto pode ocorrer secundariamente à retenção de ovos, além de outras condições que levem ao tenesmo; estas podem incluir a litíase vesical, infecções parasitárias, infecções bacterianas ou fúngicas no tecido superficial da cloaca, constipação ou, até mesmo, defeitos neurogênicos nos músculos do esfíncter cloacal (FRYE, 1991; MADER, 1996).

A primeira abordagem a ser realizada no tratamento da retenção de ovos consiste na estimulação hormonal por meio da administração de ocitocina, caso o animal não apresente prolapso de oviduto com ou sem porções necrosadas e não haja nenhuma impossibilidade mecânica à passagem dos ovos pela pelve, ou ainda quando os ovos não se apresentem quebrados ou aderidos ao oviduto. Caso o tratamento clínico não seja efetivo, deve ser realizado o tratamento cirúrgico por meio de celiotomia (DE NARDO, 1996; BRUNO et al., 1997).

Este trabalho tem como objetivo analisar os fatores predisponentes à retenção de ovos em jabutipiranga e sua correlação com outras enfermidades e ainda avaliar os tratamentos utilizados na sua resolução, estabelecendo condições ideais de uso.

\section{MATERIAL E MÉTODOS}

A investigação foi conduzida segundo o modelo de estudo de caso utilizando amostra de conveniência (FACHIN, 2001).Foram avaliadas quatorze fêmeas adultas da espécie jabutipiranga (Geochelone carbonaria) que apresentaram retenção de ovos, considerando-se os aspectos clínicos e/ou clínico-cirúrgicos e, em especial, a fisiopatologia do sistema reprodutor.

Todas as pacientes eram mantidas como animais de companhia e foram obtidas por meio do atendimento clínico no Setor de Animais Silvestres da Policlínica Veterinária da Faculdade de Veterinária (UFF), entre os anos de 1999 e 2003. As suspeitas de retenção de ovos foram estabelecidas após anamnese e exame clínico minucioso. Foram investigadas informações sobre alguns fatores, tais como presença de corpo estranho e fezes ressecadas no trato gastrintestinal, presença de doença osteometabólica, alimentação e tipo de ambiente onde os animais viviam. Em todos os casos, houve o emprego de técnicas radiográficas para o diagnóstico da retenção de ovos e para análise da estrutura óssea geral, especialmente da pelve. A avaliação óssea associada aos dados clínicos (quelônios que apresentavam amolecimento e/ou deformidades no casco) e aqueles coletados na anamnese (dieta inadequada) visou a estabelecer a ocorrência de doenças osteometabólicas, resultantes de prolongada deficiência de cálcio ou vitamina $\mathrm{D}$ ou de concentrações impróprias de cálcio e fósforo na dieta. Em relação ao piso rígido, foram considerados aqueles animais que viviam em ambientes de substrato com tais características, tendo ou não terra como substrato esporádico. Analisaram-se ainda alterações dos ovos que poderiam favorecer ou provocar a ocorrência de retenção: alterações de formato, de tamanho e hipercalcificação; e os animais que possuíam um ou mais ovos com alguma destas características foram considerados distócicos. Em dois casos, foi realizado exame necroscópico.

Os dados obtidos na avaliação radiográfica dos ovos, dos fatores que favorecem a retenção e do tipo de abordagem terapêutica utilizada foram 
submetidos à análise estatística, utilizando o teste Quiquadrado.

\section{RESULTADOS}

Houve uma média de 4,8 \pm 1,9 ovos retidos por paciente, conforme a tabela 1 . Em relação aos aspectos dos ovos que podiam favorecer a ocorrência de retenção, nove animais apresentaram ovos com alterações de formato (64,3\%), seis apresentaram ovos de tamanho aumentado (42,9\%) e nove apresentaram ovos hipercalcificados (64,3\%) (Figura 1).

Em relação aos outros fatores que favorecem a ocorrência de retenção de ovos, corpos estranhos foram detectados em oito animais $(57,1 \%)$ e fezes ressecadas no trato gastrintestinal foram diagnosticadas em seis animais (42,9\%). Além disso, cinco animais apresentaram doença osteometabólica (35,7\%) e todos viviam em ambiente de substrato rígido (Tabela 2).Prolapso de oviduto no momento do atendimento clínico ocorreu em sete animais (50,0\%), e outros dois apresentaram esta condição clínica após a administração de ocitócinos (Tabela 3). Nove dos quatorze casos estudados foram solucionados com a postura normal dos ovos (64,3\%), seja após a aplicação de ocitócinos (7 a 10UI $\mathrm{kg}^{-1}$ ) ou através de tratamento clínico de suporte. Apenas um caso $(7,1 \%)$ necessitou de tratamento cirúrgico (Tabela 3).

As análises estatísticas feitas pelo teste Quiquadrado com nível de significância de 0,05 mostraram que apenas o resultado referente ao percentual de animais que necessitaram de tratamento cirúrgico foi significativo $(0,001)$.

Quatro de treze pacientes atendidas vieram a óbito após tentativa de resolução da retenção de ovos. Uma jabota veio a óbito após o procedimento cirúrgico. As outras três morreram após tratamento de suporte, sendo que em uma delas detectou-se à necropsia a presença de corpo estranho plástico no trato gastrointestinal como possível causa mortis. Nos outros dois casos, não foi possível precisar o que levou ao óbito, pois os animais foram enterrados pelos “proprietários”.

Outro animal já chegou morto ao atendimento clínico e, durante a necropsia, observouse o oviduto com pontos enegrecidos nas áreas de mucosa que tinham contato com os ovos.

Em relação às dietas, foi possível observar que todas eram inadequadas, sendo detectados os mais variáveis tipos de alimentos entre verduras, legumes, frutas, rações de animais domésticos e restos de alimentação humana.

A ocorrência de animais com ovos retidos distribuiu-se pela maioria dos meses do ano, à exceção de julho, agosto, setembro e dezembro.

\section{DISCUSSÃO E CONCLUSÕES}

É importante considerar que, ao exame clínico, todas as jabotas apresentavam apatia e depressão, sinais clínicos inespecíficos que não ocorrem somente quando os animais apresentam distocias. $\mathrm{O}$ fato de todas as pacientes apresentarem

Tabela 1 - Aspectos dos ovos retidos de jabutipirangas (Geochelone carbonaria) atendidas na Policlínica Veterinária da UFF, entre 1999 e 2003.

\begin{tabular}{|c|c|c|c|c|}
\hline Paciente & $\mathrm{N}^{\mathrm{o}}$ de ovos & Alterações de formato & Tamanho aumentado & Hipercalcificação \\
\hline 1 & 4 & + & - & + \\
\hline 2 & 6 & + & - & - \\
\hline 3 & 2 & + & + & - \\
\hline 4 & 4 & - & + & - \\
\hline 5 & 5 & + & - & + \\
\hline 6 & 6 & + & - & + \\
\hline 7 & 6 & - & - & + \\
\hline 8 & 6 & + & + & + \\
\hline 9 & 4 & + & - & + \\
\hline 10 & 2 & - & + & - \\
\hline 11 & 8 & + & - & + \\
\hline 12 & 2 & - & + & + \\
\hline 13 & 7 & + & + & + \\
\hline 14 & 5 & - & - & - \\
\hline \multirow[t]{3}{*}{ Média } & $4,8 \pm 1,9$ & 9 & 6 & 9 \\
\hline & Ocorrência (\%) & 64,3 & 42,9 & 64,3 \\
\hline & $\mathrm{X}^{2}$ & 0,285 & 0,593 & 0,285 \\
\hline
\end{tabular}




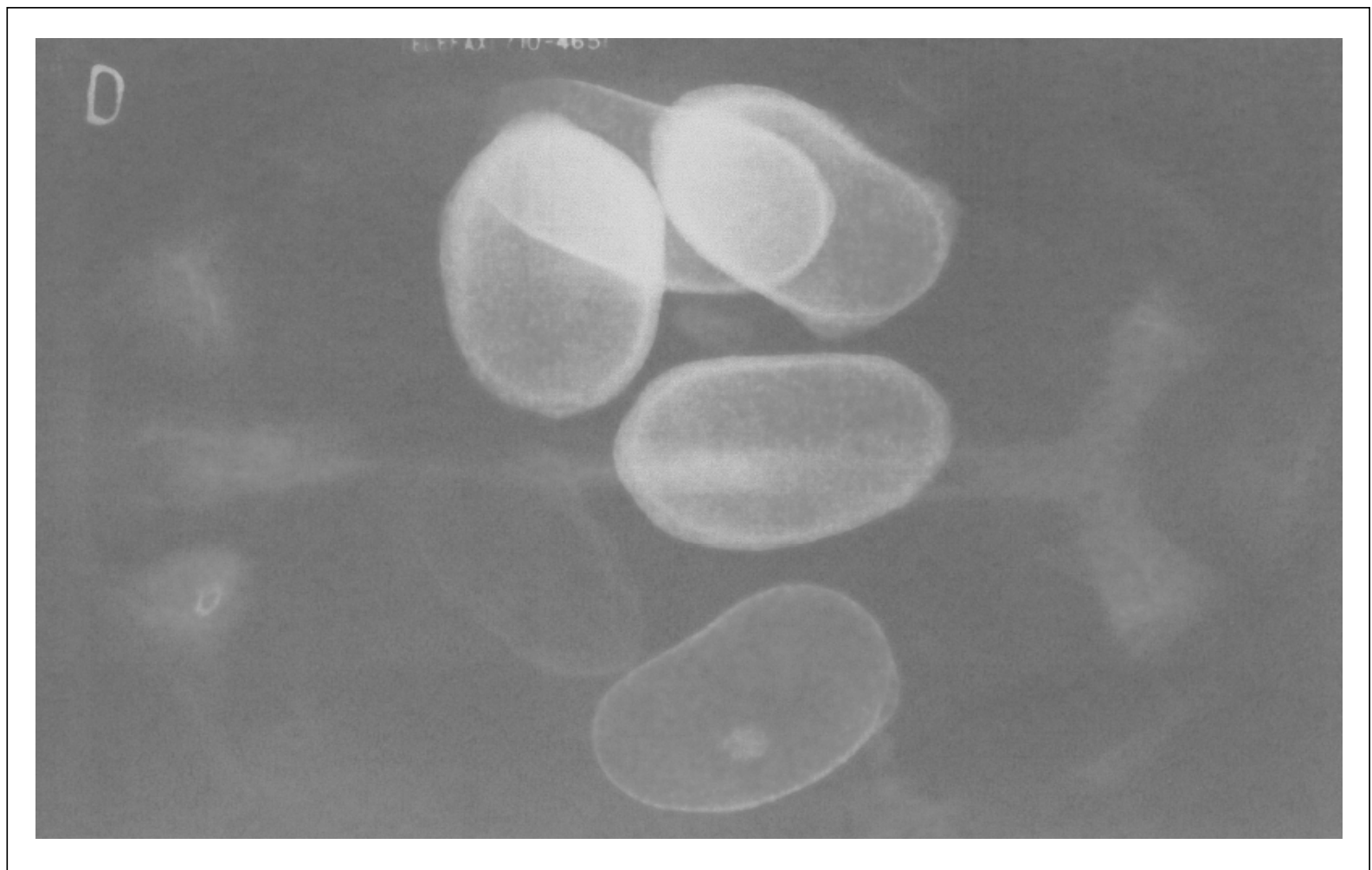

Figura 1 - Radiografia simples, na posição dorso-ventral da cavidade celomática de uma fêmea de jabutipiranga (Geochelone carbonaria), onde podem ser visualizados seis ovos, sendo que todos apresentam formato alterado e cinco apresentam tamanho aumentado e hipercalcificação das cascas.

ovos retidos ao exame radiográfico não significa necessariamente que a retenção seja a causa primária do estado clínico de apatia. DE NARDO (1996) afirmou ser impossível detectar a retenção de ovos sem exame radiográfico e que, mesmo assim, é difícil afirmar que os ovos estão retidos. De fato, o diagnóstico definitivo

Tabela 2 - Análise dos fatores que possivelmente favorecem a retenção de ovos em jabutipirangas (Geochelone carbonaria) atendidas na Policlínica Veterinária da UFF, entre 1999 e 2003.

\begin{tabular}{|c|c|c|c|c|}
\hline Paciente & Corpo estranho & Fezes ressecadas & Doença osteometabólica & Substrato rígido \\
\hline 1 & + & + & + & + \\
\hline 2 & + & - & - & + \\
\hline 3 & - & - & - & + \\
\hline 4 & - & + & - & + \\
\hline 5 & + & + & - & + \\
\hline 6 & + & + & + & + \\
\hline 7 & + & - & - & + \\
\hline 8 & + & - & - & + \\
\hline 9 & + & - & + & + \\
\hline 10 & - & - & - & + \\
\hline 11 & + & + & + & + \\
\hline 12 & - & + & - & + \\
\hline 13 & - & - & - & + \\
\hline 14 & - & - & + & + \\
\hline Total & 8 & 6 & 5 & 14 \\
\hline Ocorrência (\%) & 57,1 & 42,9 & 35,7 & 100,00 \\
\hline $\mathrm{X}^{2}$ & 0,593 & 0,593 & 0,285 & \\
\hline
\end{tabular}

Ciência Rural, v.36, n.5, set-out, 2006. 
Tabela 3 - Freqüência de prolapso de oviduto, intervenções clínica e cirúrgica e oviposturas em jabutipirangas (Geochelone carbonaria) atendidas na Policlínica Veterinária da UFF, entre 1999 e 2003.

\begin{tabular}{|c|c|c|c|c|}
\hline Paciente & Presença de prolapso & Aplicação de ocitócinos & Intervenção cirúrgica & Ovipostura \\
\hline 1 & + & - & - & + \\
\hline 2 & - & + & - & + \\
\hline 3 & + & + & - & + \\
\hline 4 & + & - & - & - \\
\hline 5 & + & - & + & - \\
\hline 6 & - & + & - & + \\
\hline 7 & + & + & - & - \\
\hline 8 & + & - & - & + \\
\hline 9 & - & + & - & + \\
\hline 10 & - & + & - & - \\
\hline 11 & - & + & - & + \\
\hline 12 & - & + & - & + \\
\hline 13 & + & - & - & + \\
\hline 14 & - & - & - & - \\
\hline Total & 7 & 8 & 1 & 9 \\
\hline Ocorrência (\%) & 50,0 & 57,1 & 7,1 & 64,3 \\
\hline $\mathrm{X}^{2}$ & 1 & 0,593 & 0,001 & 0,285 \\
\hline
\end{tabular}

de retenção de ovos requereu uma minuciosa investigação clínica. Sua associação com os achados dos exames radiográficos se mostrou de extrema importância, evidenciando, dentre outros aspectos, o tamanho dos ovos em relação à abertura da pelve, sua forma e posicionamento, assim como a possível hipercalcificação da casca.

Inicialmente pode haver dificuldade na diferenciação entre distocia e gestação normal. Geralmente, se os ovos apresentam formatos anormais, cascas espessas, sinais de depressão e, se os animais apresentam secreções cloacais, devem ser removidos. É muito importante correlacionar o diâmetro dos ovos à abertura pélvica e à ausência de movimentação dos ovos quando se compara radiografias realizadas em momentos diferentes no período de tratamento com ocitócinos. A retenção pode estar associada à aderência desses ovos à mucosa do oviduto (ibid). Isto pôde também ser observado por BRUNO et al. (1997), todavia, no presente trabalho, não houve nenhum caso com tais características.

A média de ovos retidos, de 4,8 $\pm 1,9$ nos casos estudados, além do mínimo de dois e máximo de oito ovos retidos, coincide com os estudos de ERNST \& BARBOUR (1989) ao afirmarem que a espécie jabutipiranga oviposita de 2 a 15 ovos por ninhada.

Dois animais recidivaram a retenção de ovos aproximadamente um ano depois. Isto se deu porque os fatores predisponentes detectados na primeira ocorrência da distocia não foram solucionados. DE
NARDO (1996) observou a mesma situação em seus estudos sobre a recorrência de retenção de ovos.

Uma das pacientes, mesmo apresentando ovos de formato anormal e hipercalcificados, confirmados após exame radiográfico, conseguiu realizar a oviposição sem a necessidade de administração de ocitócinos. Como o animal se encontrava bastante debilitado, optou-se por um tratamento clínico de suporte a fim de melhorar o estado geral e viabilizar a cirurgia. Entretanto, a paciente realizou postura normal três dias depois do início do tratamento. Como sugere DE NARDO (1996), este fato confirma como é importante a interpretação de cada caso de distocia para que se possa decidir o tratamento mais conveniente.

Dessa forma, consideram-se as observações de BENNET \& MADER (1996) de que as intervenções cirúrgicas são indicadas quando as técnicas clínicas não invasivas fracassaram na resolução de distocias ou quando existirem evidências de que a ovipostura não é possível. No único caso estudado em que foi inevitável a intervenção cirúrgica, o animal apresentava o oviduto prolabado há uma semana e já com áreas de dilaceração.

Nenhum dos fatores que podem favorecer a retenção de ovos ocorreu isoladamente nas pacientes: estiveram presentes no mínimo dois e no máximo seis desses fatores em cada um dos quatorze casos estudados. Desta forma, é imprescindível a análise de cada caso, objetivando o melhor direcionamento terapêutico. De fato, isto corrobora a opinião de DE 
NARDO (1996) quanto à retenção de ovos ser determinada por fatores variados, cuja etiologia muitas vezes pode não ser estabelecida.

Todas as quatorze pacientes do presente estudo viviam em ambientes com pisos rígidos ou tinham acesso esporádico e bastante limitado a ambientes com substrato de terra. Desse modo, nenhuma delas tinha condições favoráveis para preparar seu ninho. Este fato confirma as observações de BROWN \& MARTIN (1991), ao afirmarem que jabutis que não possuem no cativeiro condições de cavar seu ninho para realizar a oviposição são potencialmente susceptíveis a reterem seus ovos.

Dependendo do tempo em que os ovos estiverem retidos, podem aderir à mucosa do oviduto com possibilidade de infecção e morte por septicemia. Deve ser considerada também a ação traumática das cascas de ovos retidos sobre a mucosa do oviduto como fator importante para que ocorram possíveis aderências. MADER (1996) destaca que a cópula imposta por machos possuidores de forte libido pode provocar a quebra de ovos em fêmeas gestantes, o que pode contribuir para a retenção. Isto não foi observado em nenhum dos quatorze casos, apesar de alguns animais conviverem com jabutis machos. Por outro lado, apartar machos e fêmeas na época da postura pode diminuir a ocorrência de ovos fraturados. FRYE (1991) acrescentou que os fragmentos de casca podem provocar lacerações e rompimento da parede do oviduto com derramamento do conteúdo dos ovos, ocorrência que também não foi identificada no presente estudo.

Como descrito por FRYE (1991) e MADER (1996), o prolapso de oviduto pode ocorrer secundariamente à retenção de ovos, estando presente em cerca de $50 \%$ das pacientes estudadas. GABRISCH \& ZWART (1998) comentaram que os prolapsos de oviduto são diagnosticados especialmente em cágados e, contrariamente ao prolapso de cloaca, recidivam constantemente. Naquelas pacientes que apresentaram prolapso de oviduto, suspeitou-se de imediato da ocorrência de retenção de ovos, fato este confirmado em seguida.

O fornecimento de dieta desequilibrada, conforme afirma DE NARDO (1996), é decisivo para o estado de saúde dos animais, já que pode levar ao desequilíbrio no metabolismo e provocar uma série de estados patológicos como enfermidades hepáticas, doenças osteometabólicas e a própria retenção de ovos. SCHRAMM et al. (1999) e HUOT-DAUBREMONT et al. (2003) também fizeram menção ao estoque de gordura. Estes dois fatores estão diretamente ligados à produção de ovos, à duração da estação reprodutiva e à oviposição, os quais podem estar comprometidos se houver deficiência alimentar. No presente trabalho, percebeu-se que nenhuma das pacientes recebia uma dieta equilibrada.

Estudos sobre o perfil hormonal em espécies de jabutis são raros. SCHRAMM et al. (1999), ao estudarem o ciclo hormonal do jabuti de Galápagos (Geochelone nigra), descreveram-no como sazonal e coincidente com mudanças na temperatura e chuvas. Desta forma, a estação de acasalamento ocorre de janeiro a junho, durante a estação mais quente e de maior quantidade de chuvas, e a estação de nidificação, de maio a outubro, durante o período mais frio e seco. Estudos similares em G. carbonaria não foram realizados até o presente momento. ERNST \& BARBOUR (1989) relataram que o período de nidificação do jabutipiranga ocorre de junho a setembro e que, em cativeiro, a cópula ocorre durante todo o ano. Não houve ocorrência de animais com ovos retidos nos meses de julho, agosto e setembro, período este que coincide com o período de nidificação e postura relatado pelos mesmos autores.

A utilização de técnicas radiográficas faz-se indispensável para o diagnóstico definitivo da retenção e especialmente na avaliação dos aspectos dos ovos. Conforme observado, a decisão acerca das medidas terapêuticas a serem adotadas deve basear-se em avaliações minuciosas do estado de saúde dos animais, já que, em alguns casos, somente correções de manejo e terapia de suporte visando a uma melhora do quadro clínico foram suficientes para que a ovipostura ocorresse. A possibilidade da realização de exames complementares como hemograma, dosagens bioquímicas, coproparasitológico e laparoscopia exploratória, pode contribuir para a seleção da medida terapêutica mais adequada. A gravidade de muitos casos requer, contudo, intervenções imediatas.

O fornecimento de uma dieta desequilibrada, associado à manutenção das jabotas em ambientes com piso predominantemente rígido, demonstrou ser decisivo para a ocorrência da retenção de ovos, uma vez que todos os animais eram submetidos a esse manejo.

Seria importante o conhecimento do perfil hormonal da espécie $\boldsymbol{G}$. carbonaria a fim de melhor delimitar as fases do ciclo reprodutivo e assim correlacionar períodos de maior incidência de casos de retenção de ovos.

Por fim, considera-se que a manutenção de jabutis como animais de companhia constitui uma prática relativamente comum da população brasileira, estando na maioria das vezes desamparada pela legislação. A desinformação acerca das particularidades 
biológicas e do correto manejo dos animais torna-os susceptíveis a diversas enfermidades, dentre elas a retenção de ovos. Desta forma, o médico veterinário que atua na clínica e conservação de animais selvagens pode tornar-se um importante veículo de informação. Contudo, muitos destes animais são - considerando mais uma vez certos aspectos da cultura humana, como o desejo de posse e domínio - condicionados ao cativeiro e, como legados de família, atravessam gerações.

\section{REFERÊNCIAS}

BENNETT, R.A. Reptilian surgery: part I. Basic principles. Compendium on Continuing Education for the Practicing Veterinarian, v.11, n.1, p.10-20, 1989.

BENNETT, R.A.; MADER, D.R. Soft tissue surgery. In: MADER, D.R. Reptile medicine and surgery. Philadelphia: Saunders, 1996. Cap.27, p.287-298.

BROWN, C.W.; MARTIN, R.A. Dystocia in snakes. In: JOHNSTON, D.E . Exotic animal medicine in practice. Trenton: Veterinary learning systems, 1991. p.86-92.

BRUNO, S.F. et al. Klinische und chirurgische aspekte der legenot bei köhlerschildkröten (Geochelone carbonaria Spix, 1824). In: Jahrestagen der deutschen gesellschaft für herpetologie und terrarienkunde e. v. 1997, Dermagen. Jahrestagen der deutschen gesellschaft für herpetologie und terrarienkunde e. v. Dermagen: DGHT, 1997. p.23

DE NARDO, D. Dystocias. In: MADER, D.R. Reptile medicine and surgery. Philadelphia: Saunders, 1996. Cap.42, p.370-374.

ERNST, C.H.; BARBOUR, R.W. Turtles of the world. Washington DC.: Smithsonian Institution, 1989. 313p.
FACHIN, O. Fundamentos de metodologia. 3.ed. São Paulo: Saraiva, 2001. 200p.

FRYE, F.L. Reptile care: an atlas of diseases and treatments. Neptune City: TFH, 1991. 2v.

GABRISCH, K.; ZWART, P. Schildkröten. In: Krankheiten der heimtiere. Hannover: Schlütersche Verlag, 1998. Cap.19, p.663-750.

HUOT-DAUBREMONT, C. et al. Variation of plasma sex steroid concentrations in wild and captive populations of Hermann's tortoise (Testudo hermanni hermanni) in Southern France. General and Comparative Endocrinology, v.130, n.3, p.299-307, 2003.

MADER, D.R. Reptile medicine and surgery. Philadelphia: Saunders, 1996. 512p.

PINHEIRO, F.P.; MATIAS, C.A.R. Fauna silvestre apreendida e resgatada no estado do Rio e Janeiro no ano de 2003. In: CONGRESSO DA SOCIEDADE DE ZOOLÓGICOS DO BRASIL, 28., 2004, Rio de Janeiro, RJ. Anais... Rio de Janeiro: Fundação RIOZOO, 2004.

PRITCHARD, P.C.H. Encyclopedia of turtles. Neptune City: TFH, 1979. 895p.

SCHRAMM, B.G. et al. Steroid levels and reproductive cycle of the Galapagos tortoise, Geochelone nigra, living under seminatural conditions on Santa Cruz Island (Galapagos). General and Comparative Endocrinology, v.114, n.1, p.108-120, 1999.

ZWART, P.; VORSTENBOSCH, C.J.A.H.V. van. Abnormalities of the shell of eggs in reptiles. In: HERPETOPATHOLOGIA. FIFTH INTERNATIONAL COLLOQUIEM OF PATHOLOGY OF REPTILES AND AMPHIBIANS, 5., 1995, Alphen aan den Rijn. Proceedings... Alphen aan den Rijn: NRG Repro Facility BV's Hertogenbosch, 1995. p.233-238. 